\title{
2012: O Ano que Não Termina para a Paidéia, em Busca da Internacionalização
}

2012 parece não querer terminar para a Paidéia, tantas foram as conquistas e avanços obtidos, que pavimentam o caminho rumo à internacionalização. Em agosto de 2012, a revista completou 21 anos de história editorial e celebrou sua maturidade consolidando-se como um veículo robusto e qualificado, pleno de vitalidade e com anseio de visibilidade.

A Paidéia encerra o ano de 2012 firme em seu propósito de solidificar as bases para a internacionalização, na condição de periódico científico com classificação Qualis CAPES Periódicos A1 na área da Psicologia. Consoante com a proposta de internacionalização apresentada à Coordenação de Aperfeiçoamento de Pessoal de Nível Superior - CAPES, este periódico está empenhado em cumprir as ações traçadas nas metas estabelecidas perante a comunidade científica. Ao dar andamento à execução das ações necessárias para atingir as metas fixadas, é preciso ter em mente que metas são valores situados no tempo, índices que se pretende alcançar em determinado prazo.

Em fins de 2011 a Paidéia foi reconhecida pela CAPES como revista de excelência e com potencial para figurar entre as publicações que servem de referência no cenário da Psicologia nacional. Para honrarmos essa distinção, já em 2012 implementamos um conjunto extenso de transformações no projeto editorial, seguindo o plano de ações delineado com o objetivo de qualificar a revista para o cumprimento de sua missão, tendo por horizonte a internacionalização.

O passo mais decisivo na busca da internacionalização da ciência publicada neste periódico foi a implantação da publicação dos artigos em inglês. A maior inovação introduzida pela Paidéia, na comparação com os outros periódicos da área da Psicologia, é que pela primeira vez se disponibiliza uma versão totalmente bilíngue, ou seja, os artigos são veiculados simultaneamente em português e inglês na versão on line. Apenas na versão impressa preservamos a língua portuguesa, no caso dos manuscritos submetidos originalmente no idioma pátrio. Além dessa importante medida, a equipe responsável pela revista foi renovada e ampliada, incluindo a Comissão e o Conselho Editorial, bem como a equipe de apoio e pessoal de secretaria. As tarefas da Comissão Editorial foram segmentadas, de modo a agilizar e tornar mais rigorosa a pré-análise dos manuscritos, assim como o processo de avaliação e finalização editorial.

Foi implantada a submissão on line, o que tem facilitado a comunicação com os autores e a organização do fluxo de manuscritos em tramitação. Também foi constituído um Comitê de Tradutores Credenciados, com profissionais autônomos de reconhecido saber, que já desempenhavam essa função junto a outros periódicos brasileiros de impacto. As normas de publicação foram revistas, atualizadas e disponibilizadas em três idiomas: português, inglês e espanhol. O processo de padronização e normalização dos artigos foi aperfeiçoado e passamos a contar com o auxílio de empresa especializada na diagramação e preparação dos arquivos para edição eletrônica.

Mantivemos o investimento na conquista de novas bases indexadoras, com o acréscimo em 2012 de um importante indexador: a Redalyc. Desse modo, contamos atualmente com 13 bases indexadoras nacionais e internacionais: SciELO, Scopus, PsycINFO, PASCAL, LILACS, CLASE, PSICODOC, DOAJ, Ulrich's, Latindex, IRESIE, Redalyc e Index-Psi Periódicos. Assim, assegura-se ampla visibilidade aos artigos publicados, imprescindível para alcançarmos a meta de internacionalização.

No apagar das luzes de 2012 a revista ganhou uma nova sede. Agora está em uma sala mais ampla e adaptada com recursos de informática recém-adquiridos. Em 2012 nosso núcleo de assistência editorial recebeu apoio decisivo da Pró-Reitoria de Pesquisa da Universidade de São Paulo, graças ao empenho pessoal do Pró-reitor, Prof. Dr. Marco Antônio Zago. Também recebemos apoio da direção da Faculdade de Filosofia, Ciências e Letras de Ribeirão Preto - FFCLRP-USP e do Departamento de Psicologia, que permitiram solidificar as bases para a futura profissionalização da gestão editorial. Foram feitos investimentos na melhoria da infraestrutura administrativa e dos recursos humanos. No primeiro semestre de 2014 a revista finalmente contará com a contribuição de um funcionário - técnico administrativo - designado especialmente para coordenar os trabalhos na secretaria.

Em meio a esse turbilhão de mudanças estruturais e funcionais, concluímos o projeto de digitalização dos fascículos antigos e disponibilizamos o acervo completo da revista na biblioteca SciELO (http://www.scielo.br/paideia), em acesso livre e gratuito. Para consumar esse projeto, que foi desenvolvido em etapas e consumiu cerca de dois anos, pudemos contar com o apoio financeiro da Universidade de São Paulo - USP e do Conselho Nacional de Desenvolvimento Científico e Tecnológico - CNPq.

Em 2012, assim como vem ocorrendo regularmente nos últimos anos, conseguimos captar aportes de recursos financeiros junto ao Programa de Apoio às Publicações Científicas Periódicas da USP - por intermédio de sua Comissão de Credenciamento -, do CNPq e do Programa de Pós-graduação em Psicologia da FFCLRP-USP.

Ao cabo de três fascículos consecutivos (51, 52 e 53 do volume 22) com artigos publicados integralmente em inglês e português, pode-se afirmar que a Paidéia, de forma inequívoca, está cumprindo o papel de destaque que 
lhe cabe assumir na atual conjuntura da comunicação e divulgação científica em Psicologia no país. De fato, com a disponibilização dos artigos na íntegra em língua inglesa, o periódico está caminhando decididamente para consolidar sua posição junto às melhores revistas brasileiras, habilitando-se para se tornar, nos próximos anos, referência internacional na área da Psicologia. As medidas aqui elencadas estão sendo complementadas por um incremento do rigor na avaliação dos manuscritos submetidos, visando a aprimorar o processo de seleção e divulgação de contribuições de elevada qualidade científica.

É preciso reconhecer que os avanços sumarizados neste Editorial não poderiam ter sido alcançados sem a valiosa contribuição dos membros da Comissão Editorial da revista. A abnegação e tenacidade dos Editores Associados têm feito da Paidéia uma revista diferenciada, comprometida com a disseminação de conhecimento altamente qualificado e que persevera na busca de excelência. Nossos próximos desafios consistem em agilizar o fluxo de avaliação dos manuscritos, considerando que a contemporaneidade cada vez mais exige celeridade em relação ao tempo decorrido entre submissão e aprovação dos artigos, de modo a acelerar o tempo de publicação. A propósito, vale mencionar que as submissões on line continuam abertas o ano todo.

Este fascículo 53 da Paidéia é aberto pelo artigo Fatores Associados à Gravidez em Adolescentes Brasileiros de Baixa Renda, de Eva Diniz e Silvia Helena Koller, da Universidade Federal do Rio Grande do Sul. Trata-se de um estudo que investigou as características associadas à gravidez durante a adolescência em uma população de adolescentes brasileiros de baixa renda, com e sem experiência de gravidez. A análise multivariada revelou que a gravidez na adolescência se associou a um conjunto de variáveis - como menor idade para iniciação sexual e consumo de bebida alcoólica - que expressam a vulnerabilidade presente no contexto desenvolvimental dos adolescentes. O estudo traz subsídios relevantes para o planejamento de estratégias profiláticas para prevenção da gravidez durante a adolescência.

Na sequência, o artigo Levantamento de Problemas Comportamentais/Emocionais em um Ambulatório para Adolescentes, da autoria de Benedita Salete Costa Lima Valverde, Maria Sylvia de Souza Vitalle, Isa de Pádua Cintra Sampaio e Teresa Helena Schoen, da Universidade Federal de São Paulo, teve como objetivo identificar os principais problemas comportamentais e emocionais percebidos por adolescentes que frequentam um ambulatório de saúde. O principal problema relatado no Youth Self Report foi Ansiedade/Depressão. Meninos obtiveram maiores escores em Problemas Sociais e meninas apresentaram mais problemas em Ansiedade/Depressão. Os resultados referendam a necessidade de incorporação de profissionais de saúde mental nas equipes de saúde que assistem a população adolescente.

O estudo intitulado Relacionamentos de Amizade Íntima entre Jovens Adultos, de Diogo Araújo DeSousa, da Universidade Federal do Rio Grande do Sul e Elder Cerqueira-Santos, da Universidade Federal de Sergipe, investiga o papel dos amigos no ciclo vital. O estudo investigou as características dos relacionamentos íntimos de amizade de jovens adultos. Os resultados derivados da aplicação de três questionários mostraram que companheirismo é o aspecto mais marcante na amizade. Os autores concluíram que provavelmente existe um filtro de similaridades entre amigos nos jovens adultos.

$\mathrm{O}$ artigo seguinte, Riscos Biopsicossociais para o Desenvolvimento de Crianças Prematuras e com Baixo Peso, de Kelly Ambrósio Silveira, da Universidade Federal do Espírito Santo, e Sônia Regina Fiorim Enumo, da Pontifícia Universidade Católica de Campinas, teve por objetivo descrever e analisar as relações entre variáveis psicossociais e de nascimento e o desempenho cognitivo, linguístico, motor e comportamental em crianças nascidas prematuras e com baixo peso. O estudo identificou maior frequência de risco para problemas de desenvolvimento na área cognitiva e de linguagem expressiva. As autoras apontam a necessidade de monitoramento do desenvolvimento dessas crianças, facilitando o acesso à avaliação precoce, atividades de estimulação precoce e assistência às famílias.

$\mathrm{O}$ artigo Descrições Emocionais e Comportamentais de Eventos por Crianças Pré-Escolares, de Gabriela Pavarini, da Universidade de Cambridge, Inglaterra, e Débora de Hollanda Souza, da Universidade Federal de São Carlos, teve por objetivo investigar se o interesse por estados mentais alheios se reflete nas preferências de crianças entre quatro e seis anos de idade por descrições emocionais e/ou comportamentais de eventos, e se há correlação entre essas preferências e sua compreensão emocional. Os resultados evidenciaram um efeito de idade para a frequência de descrições emocionais e correlação entre a frequência de descrições emocionais e o nível de compreensão emocional dos participantes. As autoras concluem que esses dados são consistentes com evidências de aumento na produção espontânea de termos emocionais no período pré-escolar.

A seguir, o artigo Crenças de Pais e Mães Sobre Investimento Parental, de Tatiana Targino Alves Bandeira e Maria Lucia Seidl-de-Moura, da Universidade do Estado do Rio de Janeiro, investigou a hipótese de que o investimento parental aumenta a chance de sobrevivência dos bebês e garante a aptidão dos pais. $\mathrm{O}$ estudo teve por objetivo analisar crenças de pais e mães sobre investimento parental e o que relatam fazer para investir na criação de seu filho. Os resultados mostraram que homens e mulheres indicaram valorizar e realizar mais o investimento emocional. Mães relatam investir mais do que os pais, principalmente em relação aos cuidados. Segundo as autoras, os resultados obtidos contribuem para a compreensão das crenças e do investimento parental, notadamente dos pais, lembrando que estes frequentemente são negligenciados pelos estudos da área do desenvolvimento.

$\mathrm{O}$ artigo Representações Sociais de Professores e Policiais sobre Juventude e Violência, de Ana Lúcia Galinkin, Angela Maria de Oliveira Almeida e Vânia Cristine Cavalcante Anchieta, da Universidade de Brasília, teve por objetivo 
identificar as representações sociais que professores e policiais civis constroem sobre a violência, especialmente a violência praticada por jovens. Os participantes apontaram a família atual como uma das principais responsáveis pela violência praticada pelos jovens por se desobrigar de seu papel socializador dos filhos. $\mathrm{O}$ artigo oferece uma contribuição original ao focalizar uma problemática que vem inquietando a sociedade contemporânea e que está longe de ser equacionado.

Na sequência temos o artigo Preocupação e Insatisfação com o Corpo, Checagem e Evitação Corporal em Pessoas com Transtornos Alimentares, de Angela Nogueira Neves Betanho Campana, da Rede de Reabilitação Lucy Montoro - Centro Infantil Boldrini, Maria da Consolação Gomes Cunha Fernandes Tavares e Celso Garcia Júnior, da Universidade Estadual de Campinas - UNICAMP. O estudo avaliou aspectos da imagem corporal em uma amostra de pessoas com transtornos alimentares. Os resultados evidenciaram elevados níveis de insatisfação, comportamento de checagem, evitação e preocupação com o corpo. Os achados reforçam a importância de investigar esses parâmetros no atendimento multiprofissional das pessoas com diagnóstico de transtornos alimentares, de modo a planejar mais cuidadosamente as intervenções terapêuticas.

O artigo Discussão de Protocolo para Cuidadores de Pacientes com Câncer em Cuidados Paliativos, de Lara Mundim Moreira, Roberta Albuquerque Ferreira e Áderson Luiz Costa Junior, da Universidade de Brasília, avaliou o bem-estar global e o distress behavior de cuidadores de pacientes com câncer sob cuidados paliativos. Também foram avaliadas as dificuldades de médicos que lidam com tais pacientes. Os resultados mostraram que, nos cuidadores, maiores níveis de distress associam-se a menores escores de bem-estar global. Já na opinião dos médicos, é necessária maior integração entre os ambulatórios curativo e paliativo, o que beneficiaria o vínculo entre pacientes, famílias e profissionais. Os achados fornecem subsídios para a proposição de um protocolo de atendimento em ambulatório de cuidados paliativos.

Na sequência das contribuições, o artigo Leitura Mediada com Enfoque Sociocognitivo: Avaliação de uma Pesquisa-Intervenção, de Marisa Cosenza Rodrigues, Nathalie Nehmy Ribeiro, da Universidade Federal de Juiz de Fora, e Priscila Campos Cunha, da Universidade Estadual do Rio de Janeiro, teve como objetivo avaliar a efetividade de um programa dirigido a diversificar a prática docente de contar histórias e a promoção indireta da compreensão infantil dos estados mentais e do processamento de informação social. O estudo evidenciou o aperfeiçoamento docente na seleção de livros e na exploração dos termos mentais nas narrativas. Na perspectiva dos alunos, foram obtidas diferenças significativas quanto à linguagem mentalista e ao aprimoramento do processamento de informação social. Os resultados reforçam a viabilidade da implementação da leitura mediada com enfoque sociocognitivo na escola.

O artigo Avaliação de um Programa Psicoeducativo de Transição para a Parentalidade, de Sheila Giardini Murta, da Universidade de Brasília, Andréia Crispim Rodrigues,
Isabela de Oliveira Rosa e Silvia Guimarães de Paulo, da Pontifícia Universidade Católica de Goiás, aporta resultados da avaliação de um programa longitudinal de apoio à transição para a parentalidade por meio da avaliação de necessidades e de processo. A análise dos dados evidenciou a satisfação do casal investigado com o programa implementado, que fez uso das informações e estratégias recebidas, com impacto positivo nas dimensões da conjugalidade, melhor comunicação e solução de problemas interpessoais e da parentalidade, construção de conhecimentos sobre o desenvolvimento do bebê, mudanças em crenças sobre práticas educativas parentais violentas, responsividade na relação com o bebê e redução do estresse parental.

$\mathrm{O}$ artigo Internet como Suporte à Pessoa com Lesão Medular: Padrões de Uso e Reabilitação, de Maira Pinto Cauchioli Rodrigues e Tereza Cristina Cavalcanti Ferreira de Araujo, da Universidade de Brasília, abordou as Tecnologias de Informação e Comunicação, que estão em franca expansão na área da saúde. O estudo foi desenvolvido com o objetivo de conhecer os padrões de uso e a percepção sobre internet de pessoas com lesão medular adquirida. Constataram-se diferenças entre o tempo de uso e a influência da internet antes e após a lesão. As autoras concluem que, apesar de se verificar padrão de uso similar ao da população geral, foram identificadas especificidades que requerem atenção dos serviços especializados de reabilitação, no intuito de aprimorar rotinas de atendimento.

Finalmente, o estudo Adaptação e Validação de Instrumentos Psicológicos entre Culturas: Algumas Considerações, de Juliane Callegaro Borsa, Bruno Figueiredo Damásio e Denise Ruschel Bandeira, da Universidade Federal do Rio Grande do Sul, focalizou o processo de adaptação de instrumentos psicológicos. Os autores problematizaram alguns aspectos essenciais da adaptação transcultural de instrumentos psicológicos e propuseram diretrizes aos pesquisadores sobre os diferentes passos desse processo, contribuindo para ampliar o debate contemporâneo na área de avaliação psicológica.

Fechando o fascículo, temos a resenha Por uma Nova Compreensão do Conceito de Bem-estar: Martin Seligman e a Psicologia Positiva, de autoria de Fabio Scorsolini-Comin, da Universidade Federal do Triângulo Mineiro. Trata-se de uma apreciação bem instrutiva e convidativa do livro de Martin Seligman, Florescer: Uma Nova Compreensão sobre a Natureza da Felicidade e do Bem-estar, em tradução para o português lançada pela Editora Objetiva em 2011.

Este número se encerra com as Normas de Publicação e, na sequência, apresentamos a relação dos consultores $a d$ hoc que colaboraram com a revista em 2012. Desse modo consignamos nosso agradecimento aos especialistas que trabalharam arduamente no processo de revisão dos manuscritos submetidos à publicação.

Esperamos que todos tenham uma leitura proveitosa.

Manoel Antônio dos Santos Editor 